\title{
Vocal production in postpartum dairy cows: Temporal organization and association with maternal and stress behaviors
}

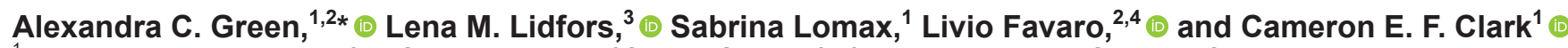 \\ ${ }^{1}$ Livestock Production and Welfare Group, University of Sydney, School of Life and Environmental Sciences, Camden 2570, Australia \\ ${ }^{2}$ Equipe Neuro-Ethologie Sensorielle, Centre National de la Recherche Scientifique, Unité Mixte de Recherche, \\ Institut National de la Santé et de la Recherche Médicale, University of Lyon/Saint-Étienne, Saint-Étienne 42023, France \\ ${ }^{3}$ Department of Animal Environment and Health, Swedish University of Agricultural Sciences, SE-532 23 Skara, Sweden \\ ${ }^{4}$ Department of Life Sciences and Systems Biology, University of Turin, 10123 Turin, Italy
}

\section{ABSTRACT}

Mammalian vocalizations can encode contextual information in both the spectrographic components of their individual vocal units and in their temporal organization. Here we observed 23 Holstein-Friesian dairy cows immediately after birth during interactions with their calf and when their calf was separated to the other side of a fence line. We investigated whether the vocalizations emitted in these postpartum contexts would vary temporally. We also described the maternal and stress behaviors preceding and following postpartum vocal production using kinematic diagrams and characterized call sequence structure. The kinematic diagrams highlight the disruption of maternal responses caused by calf separation and show that behavioral and vocal patterns varied according to the cows' emotional states and proximity to the calf in both contexts. During calf interactions, cows mainly produced closed-mouth calls simultaneous to licking their calf, whereas an escalation of stress responses was observed during calf separation, with the cows approaching the fence line, becoming alert to the calf, and emitting more mixed and open-mouth calls. Call sequences were similarly structured across contexts, mostly containing repetitions of a single call type, with a mean interval of $0.57 \mathrm{~s}$ between calls and a greater cumulative vocalization duration, attributed to an increased number of vocal units per sequence. Overall, calf separation was associated with a greater proportion of calls emitted as a sequence (inverse of single isolated calls), a shorter interval between separate call sequences, and a greater number of vocal units per sequence, compared with calf interactions. These temporal vocal features varied predictably with the high stress expression from cows during calf separation and may represent temporal modulations of emotional

Received May 13, 2020.

Accepted August 7, 2020.

*Corresponding author: a.green@sydney.edu.au expression. Despite the noisy farm soundscape, empirical call type and temporal vocal features were easy to measure; thus, findings could be applied to future cattle studies wishing to analyze vocalizations for on-farm welfare assessments.

Key words: calf separation, kinematic diagrams, maternal behavior, sequential analyses, vocalizations

\section{INTRODUCTION}

Vocalizations can provide insight into the subjective experiences of animals, including their motivational (Morton, 1977) and emotional states (Darwin, 1872; Briefer, 2012; Baciadonna et al., 2019). Compared with many physiological measures, the recording of vocalizations does not require physical interaction with the animal of interest, meaning they can be collected without interfering with the animal's expression of natural behaviors. The use of vocalizations for livestock welfare assessment has long been discussed (Watts and Stookey, 2000; Manteuffel et al., 2004; Green et al., 2018; Ede et al., 2019); however, the dynamic emotional and welfare content of cattle vocalizations requires further exploration.

Dairy cows express a high incidence of vocalizations during interactions with their calf (Lidfors, 1996) and upon calf separation (Lidfors, 1996; Weary and Chua, 2000; Flower and Weary, 2001; Stěhulová et al., 2008). During calf interactions, cows exhibit maternal behavior, including sniffing and licking their calf (Lidfors, 1996; von Keyserlingk and Weary, 2007; Jensen, 2012), alongside vocalizations (Lidfors, 1996), which may facilitate recognition from their offspring (Padilla de la Torre et al., 2016). These vocalizations, which accompany the affiliative behavioral responses, likely reflect the positive low-arousal emotions of the cow (Ede et al., 2019; Meagher et al., 2019). By contrast, calf separation is characterized by negative high arousal and elicits strong behavioral and physiological reactions in cows, even when performed immediately after birth 
(Lidfors, 1996; Weary and Chua, 2000; Flower and Weary, 2001; Stěhulová et al., 2008). These emotionally and behaviorally contrasting postpartum contexts should therefore lead to predictable changes in cow vocalizations, providing a good model for studying welfare-related vocal measures in cattle.

The static information content of free-ranging cattle vocalizations has already been comprehensively studied through spectrographic analyses (Padilla de la Torre et al., 2015; Green et al., 2019). Cattle naturally reside in herds, with their vocalizations facilitating social interactions (Padilla de la Torre et al., 2015), providing stable cues to individual identity across different emotionally valenced contexts (Green et al., 2019). However, compared with the free-ranging environment, the soundscape in a commercial production setting is often dominated by ambient noises such as those from farm vehicles, aggregations of cattle, milking machinery, farm staff, and calls of other animals cohabitating in the cattle sheds (Arnold et al., 2007). These ambient noises may influence the signal-to-noise ratio of sound recordings or lead to signal clipping (Bishop et al., 2019), which can, in turn, distort the spectrographic properties of the vocalizations. Ambient noises may also overlap in the frequency domain of the cattle vocalizations, as they contain both low-frequency (Padilla de la Torre et al., 2015; Bishop et al., 2019) and highfrequency components (Padilla de la Torre et al., 2015; Green et al., 2019), making signal filtering ineffective. However, it is important to measure vocalizations in the production environment, as replicating stressors under controlled experimental conditions may not yield commercially applicable welfare-related results. Across mammalian taxa, emotional and contextual information is communicated not only in the spectrographic properties of vocalizations but also through their temporal organization (Taylor et al., 2009; Engesser et al., 2017; Filippi et al., 2019), which may be less influenced by recording conditions. Despite increasing bioacoustics research into the emotional encoding in individual vocal units in goats (Briefer et al., 2015b), horses (Briefer et al., 2015a; Maigrot et al., 2017), and pigs (Briefer et al., 2019), the detailed temporal organization of livestock vocalizations is yet to be systematically analyzed. This presents the opportunity to study the temporal vocal features of postpartum cow vocalizations as a means of welfare detection in production environments.

Temporal vocal parameters have been shown to modulate with increasing arousal, due to sympathetic nervous system activation and consequent increases in motor activity and respiration rate (Scherer, 1986; Briefer, 2012). Increased calling rate has been associated with high situation urgency (McElligott and Hayden, 1999; Zimmerman et al., 2000; Manser, 2001;
Taylor and Reby, 2010), such as during the climax of estrus in cows (Schön et al., 2007; Röttgen et al., 2018). Simultaneously, the interval between vocal production also decreases (Blumstein, 2007; Briefer, 2012; Kershenbaum et al., 2016), leading to the production of call sequences. Call sequences contain more than 1 individual vocal unit, with both the individual vocal unit and combinations of these units encoding vital biological information such as individual identity, indexical cues about age or sex, motivational state, or emotional arousal (Favaro et al., 2014; Kershenbaum et al., 2016; Collier et al., 2017). Additionally, call type, which is classified either qualitatively or spectrographically, can differ according to the animal's positive or negative emotions (Tallet et al., 2013; Maigrot et al., 2017,2018 ) and could also provide insight into welfare state.

To evaluate the emotional content of cow vocalizations and then act on this information to alleviate welfarerelated issues, we must first understand the triggers and functions of vocal production within the production environment. In many biological studies, kinematic diagrams have been used to describe the association between behaviors and their transitional probabilities. Kinematic diagrams have visually demonstrated the escalation of aggression during stalk-eyed fly (Teleopsis dalmanni) interactions (Egge et al., 2011), the establishment of dominance in fighting cow dyads (Sartori et al., 2014), the behaviors preceding copulation in locusts (Golov et al., 2018) and dolphins (Orbach et al., 2015), and, more relevantly, the rhythmic properties of mouse songs (Castellucci et al., 2016). Accordingly, we recorded the behaviors and vocalizations of cows on a commercial dairy farm over the postpartum period. We constructed kinematic diagrams to first understand the behaviors that were associated with vocal production during calf interactions and subsequent fence line separation. We expected that the postpartum vocalizations and behaviors would differ, in line with previous research that has linked calf interactions with positive arousal (Ede et al., 2019; Meagher et al., 2019) and calf separation with negative arousal (Lidfors, 1996; Weary and Chua, 2000; Flower and Weary, 2001; Stěhulová et al., 2008). Thus, we compared the temporal organization of vocalizations between these emotionally contrasting contexts to determine whether temporal vocal features would modulate accordingly. To investigate these temporally based contextual differences, we also describe call sequence structure. Due to the anatomical and physiological similarities across mammalian taxa, we predicted that changes to the temporal vocal parameters in cows would be similar to those reported in other mammals, including humans (Briefer, 2012; Filippi et al., 2019). More specifically, we expected that 


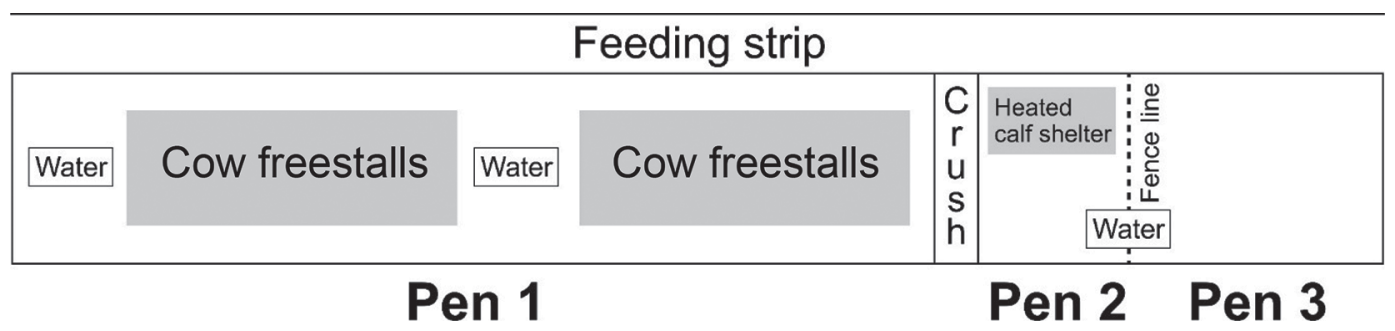

Figure 1. Diagram of the maternity barn where the cows were recorded. Pen $1(11.7 \mathrm{~m} \times 57.0 \mathrm{~m})$ contained the multiparous peripartum cows; pen $2(11.7 \mathrm{~m} \times 9.2 \mathrm{~m})$ contained the cows interacting with their calves for $60 \mathrm{~min}$; and pen $3(11.7 \mathrm{~m} \times 15.8 \mathrm{~m})$ contained the primiparous peripartum cows as well as separated cows.

with increasing situation urgency, as in calf separation, cows would vocalize at a higher rate and with shorter intervals between calls. By characterizing the temporal organization of postpartum cow vocalizations, this study uncovers new avenues for welfare-related bioacoustics research in the dairy production environment.

\section{MATERIALS AND METHODS}

\section{Farm Environment}

An observational study was conducted at a large-scale commercial dairy farm in New South Wales, Australia, between June and October 2018. This farm manages 2,000 Holstein-Friesian dairy cows, with cows housed either loose or in a freestall barn system. Calving was conducted year-round, with primiparous cows mated with a bull and multiparous cows artificially inseminated. Cows were milked 3 times a day, with all cows monitored by experienced farm staff $24 \mathrm{~h} / \mathrm{d}$. All procedures followed the farm's protocols for postpartum cows, and animal ethics approval was granted through the University of Sydney Animal Ethics Committee (Sydney, Australia; project number 2016/1078).

\section{Housing and Feeding}

Cows were housed according to their production status, with pregnant cows moved to a maternity barn (Figure 1) 2 wk before their intended date of parturition. New cows were introduced to the maternity barn once weekly, with cows grouped according to their parity. Multiparous cows were housed in a freestall section of up to 65 animals (pen 1), and primiparous cows were loosely housed in pens of up to 12 animals (pen 3 ). The multiparous cows had access to $68(34 \times 2)$ freestalls, which contained soft sand bedding that was raked daily, whereas pens 2 and 3 were mainly covered in soft sand bedding that was replaced weekly. The rest of the barn had grated concrete flooring, which was flushed daily. All cows were offered a TMR diet ad libitum at a feeding strip with self-locking head gates. All cows had access to feed concurrently, with feed offered 3 times a day. Cows also had free access to water in troughs positioned throughout the maternity barn. At 0700 and $1500 \mathrm{~h}$, cows that had calved that day were moved to the milking barn.

\section{Focal Animals}

We observed 24 cows (mean age: 43 mo, range: $23-78$ mo; mean parity: 2.58 , range: $1-5$ ), between 0630 and $1430 \mathrm{~h}$. These cows were opportunistically selected as they calved during observation hours. Cows were recorded during interactions with and separation from their calf. Only 1 cow was recorded at a time, with all cows distinguishable by their unique coat markings, ear tags, and collar numbers. Given their regular handling, all cows were habituated to human presence before the commencement of our observations.

\section{Recording Contexts}

Context here describes the farming situations in which the cows were observed and vocalized. A total of $60 \mathrm{~min}$ of calf interactions were recorded soon after parturition, once the cow had free access to her calf: when she was released from the head bail if she received calving assistance, or when she was moved with her calf to an area free from disturbance (Figure 1, pen 2 ). Calf interactions involved the mother sniffing and licking the calf and licking any birthing fluids nearby. During calf interactions, calves were ear-tagged and intubated with an esophageal tube and fed up to $4 \mathrm{~L}$ of heated high-quality colostrum by the farm staff. Occasionally calves vocalized when this feeding was delayed and upon intubation; however, due to their low occurrence, these vocalizations were not further analyzed. The multiparous cows $(\mathrm{n}=16)$ all had calf interaction experience, having previously calved under the same farming protocols. Due to the group-housing environment, 1 cow did not interact with her calf within the 
60 min observation period, as she bonded to 3 other calves nearby. For this cow, data were excluded from further analyses, resulting in 23 cows for both recording contexts.

A total of $60 \mathrm{~min}$ of vocalization and behavior after calf separation was recorded immediately once the farmer moved the cow to the other side of a fence line barrier (Figure 1, pen 3). The farmer separated the cow-calf pair soon after birth (separation time, mean: 93 min, range: 57-136 min postpartum), terminating any calf interaction that was occurring. The fence line barrier enabled both the cow and the calf to maintain visual, auditory, and some physical contact, and on occasion cows were able to lick the calf by stretching their neck over the fence or placing their head through the bars. Due to the high calving activity on this commercial farm, pen 2 housed multiple calves concurrently (mean: 5 calves, range: $1-10$ calves). Twice daily at 1000 and $1500 \mathrm{~h}$, these calves were collected and moved to individual housing in another shed. Cows selected for our study were not recorded during this time, as they had already been moved to the milking unit.

\section{Behavioral Analyses}

A video camera (Sony HDR-AS300 Action Cam, Sony Australia Limited, North Sydney, Australia) was attached to the fence line to record the behaviors of the 23 focal cows, and audio was simultaneously recorded onto a Marantz PMD661 MK2 digital solid-state recorder (stereo input, sampling rate: $44.1 \mathrm{kHz}$; Marantz Professional, Cumberland, RI). A Sennheiser ME67 shotgun microphone (frequency response: 40-20,000 $\mathrm{Hz}$, max SPL: $125 \mathrm{~dB}$ at 1,000 Hz; Sennheiser Electronic GmbH and Co., Wedemark, Germany) covered with a Rycote Classic Softie Windshield (Rycote Microphone Windshields, Stroud, UK) was directed toward the focal cow to enhance detection of her vocalizations among the farm soundscape.

Video and audio files were imported into BORIS version 7.4.14 (Friard and Gamba, 2016), for continuous behavioral analyses during the $60 \mathrm{~min}$ each of calf interactions and separation. All videos were analyzed in a random order, by a single observer who was blind to the parity of the focal cow. Behaviors that had previously been linked with dairy cow maternal (Lidfors, 1996) or stress responses (Weary and Chua, 2000; Johnsen et al., 2015) were measured (Table 1). Vocalizations were additionally quantified due to their previous link with emotional arousal (Briefer, 2012) and welfare assessment in cattle (Green et al., 2018). Vocalizations were visually and aurally classified as low fundamental frequency closed-mouth calls, high fundamental frequency open-mouth calls, or mixed calls (Table 1), depending on mouth configuration at the time of vocal production and compression of the cow's diaphragm. In instances where call type was ambiguous, narrow-band spectrograms were additionally reviewed in Praat version 6.1.04 (Boersma and van Heuven, 2001) to confirm the empirical call type (Figure 2), by assessing the fundamental frequency of the vocalizations, including whether it was stable or changed throughout the duration of the call.

As per previous vocal research (Castellucci et al., 2016), we examined the bimodal distribution of the call interval duration (Appendix Figure A1) and visualized waveforms (Figure 3), to classify calls that were more than $1 \mathrm{~s}$ apart as separate sequences. Sequences containing only an individual call with more than $1 \mathrm{~s}$ of silence preceding or following the call were deemed "single isolated calls," whereas sequences containing 2 or more successive vocalizations (Kershenbaum et al., 2016) that were less than $1 \mathrm{~s}$ apart were deemed "call sequences." Various temporal and quantitative vocal

Table 1. Ethogram of behaviors observed in the focal cows during calf interactions and calf separation $(\mathrm{n}=23)$

\begin{tabular}{|c|c|c|c|}
\hline Behavior & Definition & Recording context & $\begin{array}{l}\text { Reference to previous } \\
\text { postpartum cow studies }\end{array}$ \\
\hline Touching calf & Animal is sniffing or licking calf & Calf interactions & (Lidfors, 1996) \\
\hline Alert to calf & $\begin{array}{l}\text { Animal has attention focused and is looking in } \\
\text { direction of calf }\end{array}$ & $\begin{array}{l}\text { Calf interactions, calf } \\
\text { separation }\end{array}$ & (Johnsen et al., 2015) \\
\hline Closed-mouth call & Animal is vocalizing with the mouth closed & $\begin{array}{l}\text { Calf interactions, calf } \\
\text { separation }\end{array}$ & (Johnsen et al., 2015) \\
\hline Mixed call & $\begin{array}{l}\text { Animal is vocalizing with parts of the call produced } \\
\text { with the mouth closed and open }\end{array}$ & $\begin{array}{l}\text { Calf interactions, calf } \\
\text { separation }\end{array}$ & Not previously reported \\
\hline Open-mouth call & Animal is vocalizing with the mouth fully open & $\begin{array}{l}\text { Calf interactions, calf } \\
\text { separation }\end{array}$ & (Johnsen et al., 2015) \\
\hline Close to fence line & $\begin{array}{l}\text { Animal is within } 2 \mathrm{~m} \text { of the calf separation fence } \\
\text { line }\end{array}$ & Calf separation & (Johnsen et al., 2015) \\
\hline Fence interaction & $\begin{array}{l}\text { Animal is pressing nose on the separation fence line } \\
\text { or has their head extended over it }\end{array}$ & Calf separation & $\begin{array}{l}\text { (Weary and Chua, 2000; } \\
\text { Johnsen et al., 2015) }\end{array}$ \\
\hline
\end{tabular}




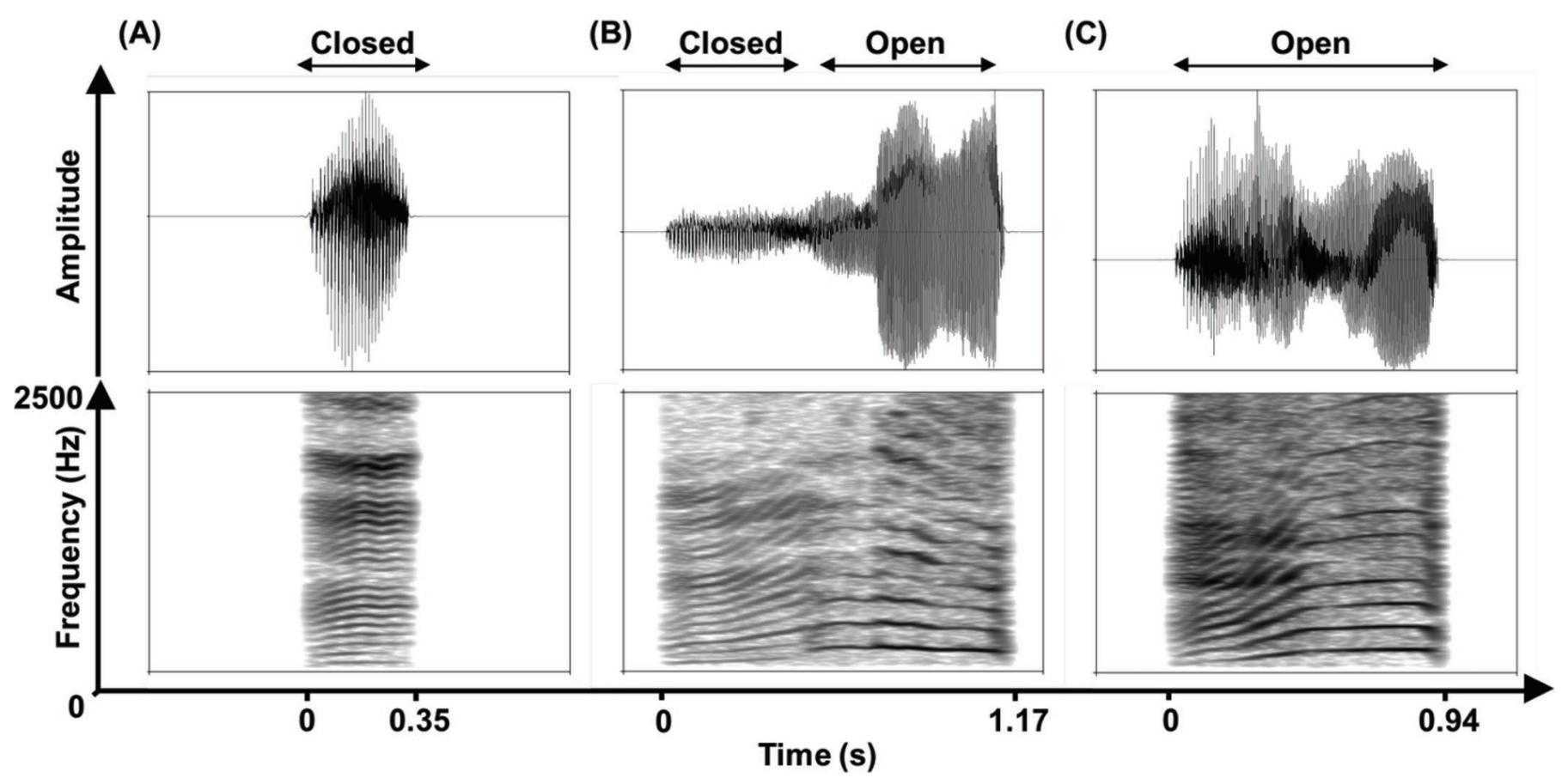

Figure 2. Sample waveforms (top) and narrow-band spectrograms (bottom) of the empirically classified (A) closed-mouth call emitted during calf interactions, (B) mixed call emitted during calf separation, and (C) open-mouth call emitted during calf separation.

parameters were then measured for the cows during calf interactions and separation. For all recordings, we quantified (1) the number of closed, mixed, and openmouth call types. A total of $53 \%$ of the sound recordings were then discarded from further analyses due to difficulties encountered with the farm soundscape, including overlapping vocalizations from nonfocal animals, reverberation due to the large presence of metal in the barn, and contamination from high-amplitude ambient noises. Nonetheless, our total sample size of 4,143 calls from 23 cows is considerably larger than those of previous postpartum cow vocalization studies (Lidfors, 1996; Weary and Chua, 2000); thus, we believe it is a representative sample for vocalization analysis. For recordings where vocalization start and end was clearly visible on the spectrogram ( $42 \%$ of total calf interaction and $53 \%$ of total calf separation calls, respectively), we measured (2) the proportion of single isolated calls (inverse of call sequence proportion) and (3) the betweensequence interval. For calls belonging to call sequences, we additionally measured (4) the number of calls in each sequence; (5) the cumulative call sequence duration (seconds); (6) the within-sequence interval, defined as the duration of silence (seconds) between the end of 1 call and the beginning of the following call of the same sequence; and (7) the type of call sequence, either being repetitive and containing a single call type or containing a combination of different call types.

\section{Sequential Analyses}

After coding the behavior, we analyzed the behavioral sequences with Behatrix version 0.9.2 (Friard and Gamba, 2019) to determine frequency of behavioral

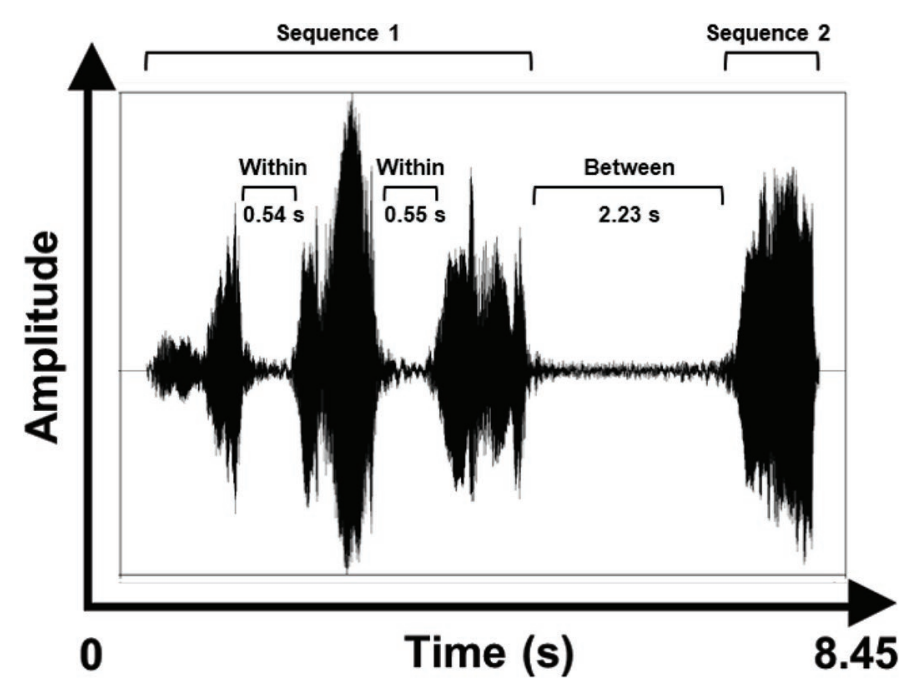

Figure 3. Sample waveform of a sequence containing 3 successive vocalizations followed by a separate sequence containing a single isolated call. The within-sequence call interval was measured in sequence 1 , whereas the between-sequence call interval was measured between sequences 1 and 2 . 
occurrences. Because multiple behaviors could occur concurrently, to simplify the analyses, all behaviors were adjusted to be mutually exclusive. The frequencies of behavioral transitions and transitional matrices were calculated for calf interactions and calf separation separately. Using the transitional matrices, permutation tests were then computed (function "run random permutations": 10,000 permutations, first and last behavior blocked), and, in conjunction with the Graphviz version 2.38 package (Ellson et al., 2003), 2 kinematic diagrams were constructed. These diagrams visually display the maternal and stress behaviors preceding and following vocal production of closed-mouth, mixed, and open-mouth calls. The kinematic diagrams display only transitional probabilities that are $>5 \%$, and transitional probabilities are reported as whole numbers with 0 decimal places. The numbers on the kinematic diagrams represent transitional probabilities, with arrows indicating directionality. Line thickness represents the significance of each transition, with significant transitions indicating behaviors that were likely to precede and follow each other. Self-transitions were also included in the diagrams, to show repetitive behavioral responses.

\section{Statistical Analyses}

Statistical analyses were performed with R Studio version 1.2.5001 (RStudio Team, 2020), an integrated development environment for $\mathrm{R}$ ( $\mathrm{R}$ Core Team, 2020), with a series of generalized linear mixed models (GLMM) and linear mixed models (LMM) run using the lme4 package (Bates et al., 2015). For the count data (number of closed-mouth, mixed, and openmouth calls and number of vocal units per sequence), GLMM were fitted with negative binomial distribution and a log-link function to minimize the occurrence of overdispersion. In these models, the vocal parameter was the response variable, context (calf interactions or separation) was the categorical fixed effect, and cow ID was the random effect to control for repeated measures from the same individual. Residuals were graphically checked using the DHARMa package (Hartig, 2019), and the dispersion of these models was confirmed using the overdisp_fun function (Bolker et al., 2009). The GLMM were also fitted with binomial distribution and a logit-link function, including the response variables of call production type (single isolated call or call sequence) and call sequence type (repetition or combination). Again, the categorical fixed effect was context (calf interactions or separation), and cow ID was the random effect to control for repeated measures from the same individual.
Linear mixed models were also run for the continuous response variables, fit with Gaussian distribution and an identity link function, first, with the betweensequence interval as the response variable, context (calf interactions or separation) remaining as the categorical fixed effect, and cow ID remaining as the random effect. A second LMM was run with call sequence duration as the response variable, context (calf interactions or separation), and number of vocal units per sequence as the fixed effects and cow ID remaining as the random effect. A final LMM was run for the within-sequence interval as the response variable, context (calf interactions or separation) as the categorical fixed effect, and call sequence ID nested within cow ID as the random effect to control for repeated calls in the same sequence and from the same cow. Residuals were inspected graphically through histograms, qqplots, and plots of residuals against fitted values. To satisfy the assumptions of normal distribution and heteroscedasticity, we logtransformed the between-call interval and call sequence duration response variables. All models (GLMM and LMM) were fitted by maximum likelihood estimation. For all vocal parameters, we assessed the significance of the fixed effects by comparing full models, including fixed and random effects, with null models comprising only the random effects, using likelihood ratio tests and the ANOVA function. Full models were selected based on their significant chi-squared values and lower Akaike's information criterion (Akaike, 1974) scores (Appendix Table A1). Post hoc comparisons were then carried out for significant full models, using the "emmeans" package (Lenth et al., 2019). In the results, we report the estimated marginal means, along with their standard errors and confidence intervals on the backtransformed scale. $P$-values of $<0.05$ were considered statistically significant, and those between 0.05 and 0.1 were considered statistical tendencies for all tests.

\section{RESULTS}

\section{Vocal Production and Association With Postpartum Behaviors}

During calf interactions, the most frequently occurring behavior expressed by the 23 cows was closedmouth vocalizations $(53.6 \%)$, followed by touching the calf $(19.2 \%)$, alert behavior to the calf $(16.9 \%)$, and then open-mouth $(5.6 \%)$ and mixed calls $(4.7 \%)$. By contrast, for the 23 cows during calf separation, alert to the calf was the most frequently occurring behavior (26.1\%), followed by closed-mouth calls $(24.1 \%)$, close to fence line behavior (18.5\%), open-mouth calls (12.0\%), fence interactions $(9.9 \%)$, and then mixed calls $(9.4 \%)$. 
Kinematic diagrams of the behavioral transitions are displayed in Figures 4 and 5 for calf interactions and calf separation, respectively. Here, we report the behavioral transitions that were most frequently occurring and significant in the kinematic diagrams. Within the calf interaction context, the behavioral patterns of the cows varied according to calf location. When distanced from the calf, before any touching, the cow repeatedly emitted mixed calls. This transitioned to open-mouth calling, or to directly touching the calf. Open-mouth calls were repeated and then transitioned to touching the calf. Alert behavior, including looking at the calf, self-transitioned but was not involved in any other significant behavioral transitions. After approaching and touching the calf, the cow proceeded to vocalize with the mouth closed. These closed-mouth vocalizations were then expressed continuously, acting as a behavioral end point.

During fence line calf separation, cows expressed an escalation of stress responses, starting with approaching the fence line and being alert to the calf. The cows then transitioned to emitting closed-mouth calls or mixed calls. Closed-mouth calls self-transitioned, whereas mixed calls were repeated and then transitioned to open-mouth calls. These open-mouth calls were then repeatedly expressed. Following the production of closedmouth calls, behavioral transitions involved the cows interacting with the fence by nose-pressing or putting their head over the bars to contact the calf. These fence interactions also self-transitioned. The cows remained close to the fence line or returned to this position after the production of closed-mouth calls, mixed calls, and open-mouth calls. Alertness to the calf was additionally followed by the cow approaching the fence line.

\section{Organization of Vocalizations Postpartum}

Some of the measured vocal parameters differed according to the postpartum context (Table 2). During interactions with the calf, cows produced more lowfrequency closed-mouth calls, whereas during calf separation, mixed and high-frequency call types were more prevalent (Table 2). Cows emitted more single isolated calls during interactions with the calf than during calf separation, with time between separate call sequences longer for calf interactions than during calf separation

\section{Calf interactions ( $n=23$ cows)}

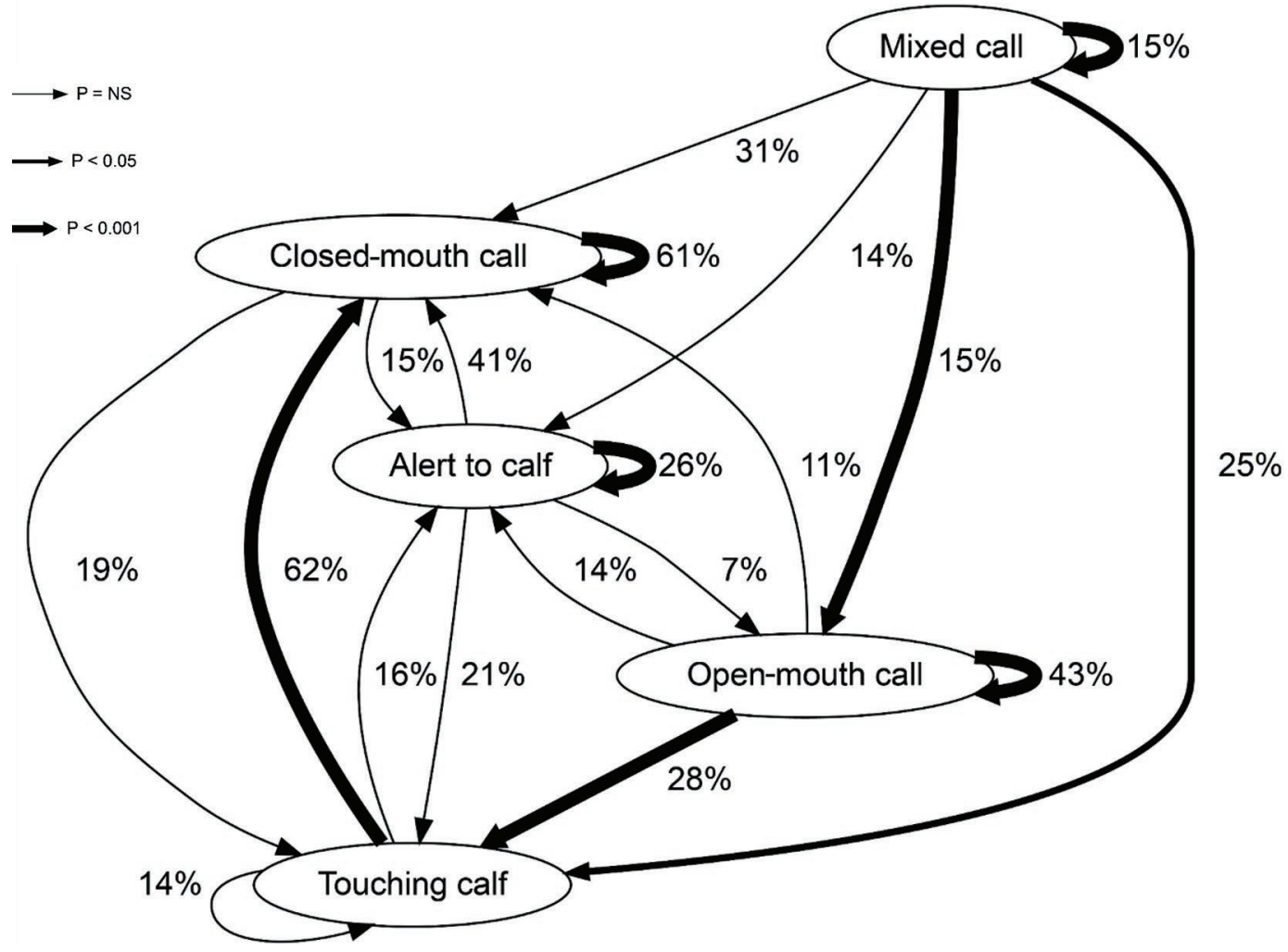

Figure 4. Kinematic diagram of the behavioral transitions preceding and following vocal production in postpartum dairy cows during interactions with the calf. Percentages indicate the transitional probabilities, with the thickest lines corresponding to a $P<0.001$ level of significance, the second-thickest lines corresponding to a $P<0.05$ level of significance, and thin lines representing nonsignificance. 


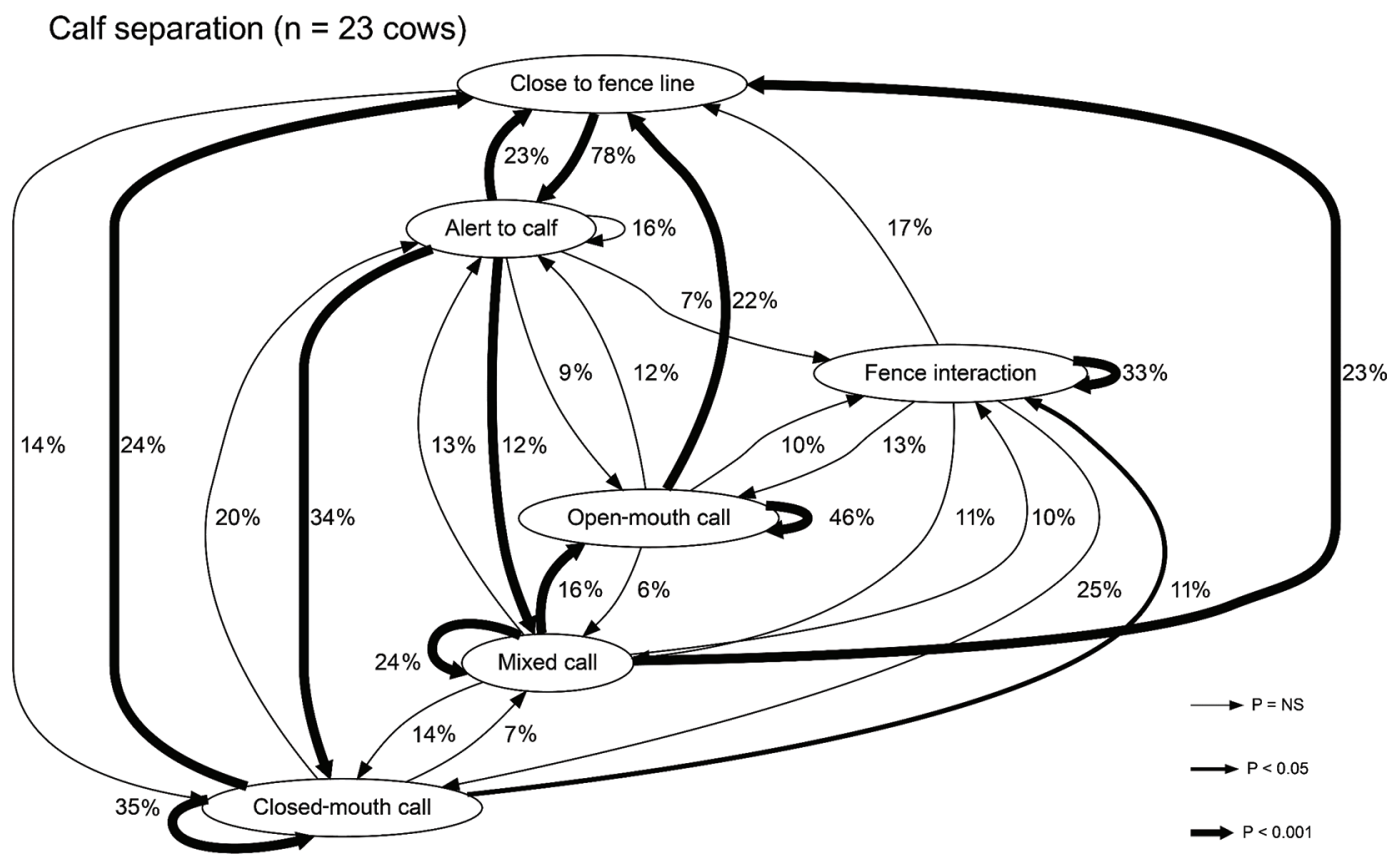

Figure 5. Kinematic diagram of the behavioral transitions preceding and following vocal production in postpartum dairy cows during separation from the calf. Percentages indicate the transitional probabilities, with the thickest lines corresponding to a $P<0.001$ level of significance, the second-thickest lines corresponding to a $P<0.05$ level of significance, and thin lines representing nonsignificance.

(Table 2). Vocal sequences contained a greater number of individual vocal units during calf separation than for calf interactions (Table 2). However, no other differences were found in the composition of the vocal sequences for the postpartum contexts. Overall, call sequences had a mean within-call sequence interval of $0.57 \mathrm{~s}$ (range: $0.14-1.0 \mathrm{~s}$ ). As the number of individual vocal units increased in the sequence, so did the cumulative duration of vocalizing $(t$-value $=20.09, P<0.0001)$; however, the cumulative duration of vocalizing did not differ between calf interactions and separation (Table 2 ). Further, $60 \%$ of call sequences involved repetition of the same call type, as opposed to a combination of call types.

\section{DISCUSSION}

We provide a comprehensive, quantitative description of the behavioral progression to vocal production in Holstein-Friesian dairy cows during calf interactions and calf separation soon after calving. We found significant context-related variation in some acoustic features of postpartum cow vocalizations, likely reflecting differences in emotional state and thus welfare of the emitters. We additionally describe the call sequence structure of cow vocalizations in terms of their temporal organization and call composition. These vocal findings inform us about the emotional progression of postpartum dairy cows from reacting positively while

Table 2. Post hoc comparisons of vocal parameters during calf interactions and calf separation

\begin{tabular}{|c|c|c|c|c|c|c|}
\hline Vocal parameter & \multicolumn{2}{|c|}{ Calf interactions } & \multicolumn{2}{|c|}{ Calf separation } & $\begin{array}{l}\text { Z-ratio/ } \\
\text { T-ratio }\end{array}$ & $P$-value \\
\hline Mixed calls (no.) & $5.99 \pm 2.16$ & $2.96-12.2$ & $23.19 \pm 7.84$ & $11.95-45.0$ & $\mathrm{Z}=-4.42$ & $<0.0001$ \\
\hline Open-mouth calls (no.) & $1.62 \pm 0.94$ & $0.52-5.02$ & $8.03 \pm 4.34$ & $2.79-23.14$ & $\mathrm{Z}=-4.26$ & $<0.0001$ \\
\hline Vocal units per sequence (no.) & $2.42 \pm 0.28$ & $1.92-3.04$ & $2.95 \pm 0.30$ & $2.42-3.60$ & $\mathrm{Z}=-1.96$ & 0.0495 \\
\hline Single isolated calls (proportion) & $0.96 \pm 0.01$ & $0.93-0.98$ & $0.92 \pm 0.03$ & $0.85-0.96$ & $\mathrm{Z}=8.11$ & $<0.0001$ \\
\hline
\end{tabular}

${ }^{1}$ Z-ratio/T-ratio $=$ related to the $\mathrm{Z}$ statistic and T statistic, respectively, derived from the parameter estimate/SE, where calf interactions were coded as the reference group. 
interacting with their calf, to reacting negatively while separated from them. This may encourage the dairy industry to adopt practices allowing for cow and calf contact on commercial dairy farms. These vocal findings also broaden our understanding of cattle vocal communication in the production environment, an area of research that was previously quite limited.

The kinematic diagrams assisted with the delineation of cow behaviors during calf interactions and separation, showing a changing temporal relationship between vocalizations and behaviors across the contexts. Unlike during calf interactions, where closed-mouth calls occupied the behavioral end point, with no significant behavioral transitions afterward, calf separation vocalizations were followed by transition either to fence line interactions or back to the original behavioral state of being close to the fence line, where the cycle continued. These transitions highlight the overall disruption to maternal behavior and escalation of stress triggered by the fence line separation procedure. Although overall differences were detectable in the behavioral sequences across contexts, the 3 empirical call types - namely closed, mixed, and open-mouth calls - expressed during calf interactions and separation were similar in their communicative functions and potential emotional encoding. In both postpartum contexts, closed-mouth calls mostly functioned in short-distance communication, with the calf being the intended signal receiver. During the interaction context, upon sniffing and licking the calf, the cows emitted closed-mouth calls. The repeated emission of these nasally produced calls could steadily indicate positive social behavior toward the calf, to which the cow expresses maternal and affiliative bonds (Mellor, 2015). Even during calf separation, repeated closed-mouth calling led to recurrent fence interactions, including nose-pressing of the bars and extension of the head over the bars into the calf pen, further highlighting the possibility of positive emotional expression in closed-mouth calls upon making some contact with the calf. The closed-mouth calls could have also facilitated calves' recognition of their mothers (Lidfors, 1996; Padilla de la Torre et al., 2015), which is biologically relevant because cattle are a hider species, often concealing their calves to minimize predation risk and relying on auditory cues for communication (Padilla de la Torre et al., 2016).

The mixed calls of the present study, which were emitted during higher urgency than their closed-mouth counterparts, represent an intermediate form of the low-frequency and high-frequency calls commonly reported in the literature (Johnsen et al., 2015; Padilla de la Torre et al., 2015). This study is the first to report recordings of mixed calls in postpartum dairy cows. The significant transition of mixed calls, which con- tain both closed- and open-mouth components, to fully open-mouth calling during both postpartum contexts complements the idea of a graded cattle vocal repertoire (Kiley, 1972), likely reflecting a continuum of emotional expression from cows during both postpartum contexts. Call sequences comprising various combinations of the 3 call types were also observed in both postpartum contexts. During calf interactions, before physical contact with the calf, cows would repeatedly emit mixed calls, which transitioned to repetitive open-mouth calling. The mixed and open-mouth calls were followed by the cow approaching and touching the calf, suggesting that calls with a more open-mouth configuration and subsequent higher amplitude function in longer-distance communication. High-frequency calls, which are produced with a mixed or open-mouth configuration, have also been observed in free-ranging cattle upon brief visual separation from their calves (Padilla de la Torre et al., 2015), suggesting that these calls could be a way to express emotion, such as increased urgency when cows are distanced from their calves. Indeed, calls with a more open-mouth configuration were overall more prevalent during calf separation, whereas calf interactions led to more closed-mouth calls. Hence, despite bonding with the calf for only $60 \mathrm{~min}$, the high emission of openmouth calls suggests that cows were still stressed by the separation procedures. Modifications to call type proportions are suggested to represent changes in emotional valence (Tallet et al., 2013; Maigrot et al., 2017, 2018), and in wild and domesticated pigs, call types with a higher fundamental frequency, like the present mixed and open-mouth calls, were more prevalent during negative situations (Tallet et al., 2013; Maigrot et al., 2018).

We show that some temporal vocal parameters vary predictably with the postpartum contexts, likely reflecting emotionally induced changes, as in previous studies that have shown context-related acoustic differences in individual cattle vocalizations (Yeon et al., 2006; Meen et al., 2015). In calf separation, the overall greater proportion of vocal sequences (inverse of proportion of single isolated calls), together with the greater number of vocal units per sequence and shorter interval between separate call sequences is suggestive of a higher arousal state. Indeed, calf separation is stressful to cows (Lidfors, 1996; Flower and Weary, 2001), and these results correspond with vocal correlates of arousal or high urgency in other mammalian taxa (Yin and McCowan, 2004; Taylor et al., 2009; Briefer, 2012; Scheumann et al., 2012). These vocal parameters change with increasing arousal due to changes to the sympathetic nervous system, which affect respiration rate and tension of the muscles in the vocalizing animal (Scherer, 1986; Briefer, 2012). Together, these temporal features may act to 
improve the salience of the signal (Yin and McCowan, 2004), relaying information to conspecifics about the urgency of the situation (Manser, 2001) and resultant welfare state of the vocalizer.

Despite contextual differences in the aforementioned vocal parameters, across contexts vocal sequences were similarly structured in their sequence type, cumulative call duration, and intervals of silence. Repetitive calling of the 3 empirical call types was observed in both postpartum contexts, being more common than combination call sequences. The repetitive broadcasting of a single call type may indicate a persistent emotional state at the time of vocalizing (Collier et al., 2017), reflecting high urgency of the situation (Kershenbaum et al., 2016), and may function to enhance signal reception in noisy environments (McElligott and Hayden, 1999) such as a commercial farm. Emotions are shortlived reactions to stimuli (Briefer, 2012), and although calf separation was overall more consistent with a higharousal negative state, the emission of sequences during both postpartum contexts may represent the fluctuations of behavior and emotions that were also experienced within context. Although free-ranging cattle have previously been shown to vocalize with an average of 5.32 calls per sequence and an intercall interval of $2.71 \mathrm{~s}$ when making social contact (Padilla de la Torre et al., 2016), these values are likely to vary according to the contexts and subsequent emotions or motivations of the cow. These values may also depend on what is considered to constitute a vocal sequence. Unlike in red deer (Cervus elaphus), where sequences are clearly defined by containing a series of calls emitted upon a single exhalation (McComb, 1991), in the current study we observed cows generally inhaling after each vocalization. We therefore categorized calls into the same sequence if they were less than $1 \mathrm{~s}$ apart based on the trough in the distribution of the silence intervals. Calls in the same sequence were also accompanied by steady behavioral states, such as touching (i.e., sniffing and licking) the calf during interactions or vision of the calf during separation, further justifying this methodological approach. Thus, these results provide an important reference for future studies wishing to assess the vocal sequences of cattle.

Despite clear contextual differences in postpartum cow behaviors and vocalizations alike, we were unable to distinguish whether these changes were more associated with the independent arousal or valence emotional dimensions, as in previous work (Briefer et al., 2015a,b). We conducted an observational study based on the high incidence of vocalizations previously reported in each of the postpartum contexts (Lidfors, 1996; Weary and Chua, 2000; Flower and Weary, 2001; Stěhulová et al., 2008), as opposed to other routine farming procedures.
To decipher vocal indicators of the arousal and valence dimensions separately, a controlled experimental study involving a greater number of farming contexts for each arousal and valence level could be conducted, with physiological indicators of emotion, such as heart rate variability, also measured to quantify the sympathetic nervous system changes that covary with the behavioral and vocal responses. Although heart rate has previously been shown to accelerate immediately after calf separation (Stěhulová et al., 2008), heart rate variability may more sensitively detect prolonged arousal-mediated changes in cows, as it has in other peripartum contexts (Kovács et al., 2015). To confirm the function and emotional encoding of the 3 empirical call types as well as the structure of call sequences, playback experiments should also be performed to examine the behavioral responses of signal receivers, including calves.

\section{CONCLUSIONS}

This study provides a detailed description of the behavioral progression to vocal production in postpartum dairy cows, with kinematic diagrams visually depicting the differences in behavioral organization triggered by the fence line separation procedure. This study also uncovers differences in the empirical call types and the temporal organization of vocalizations during calf interactions and calf separation, potentially reflecting their emotional encoding. Calf separation is a stressful procedure compared with calf interactions, leading to a greater proportion of mixed and open-mouth calls, higher proportion of vocal sequences, greater number of vocal units per sequence, and shorter interval between call sequences. Call sequences were similarly structured across postpartum contexts, mostly involving repetition of the same call type, with a variable number of calls emitted in each sequence. These findings can be applied to study cattle welfare from different vocal features.

\section{ACKNOWLEDGMENTS}

We are extremely grateful to the farm staff for allowing us to use their resources. Special thanks to the undergraduate students who assisted with the data collection and processing. We also acknowledge the Sydney Informatics Hub (University of Sydney, Sydney, Australia), in particular Christopher Howden and Kathrin Schemann, for their guidance on statistical methods. Author A. G. was supported by a Research Training Program scholarship funded by the Australian Government, Department of Education, Skills and Employment (Canberra, ACT, 2601 Australia). The authors declare that there are no conflicts of interest. 


\section{REFERENCES}

Akaike, H. 1974. A new look at the statistical model identification. IEEE Trans. Automat. Contr. 19:716-723. https://doi.org/10 $.1109 /$ TAC.1974.1100705.

Arnold, N. A., K. T. Ng, E. C. Jongman, and P. H. Hemsworth. 2007. The behavioural and physiological responses of dairy heifers to tape-recorded milking facility noise with and without a pre-treatment adaptation phase. Appl. Anim. Behav. Sci. 106:13-25. https: //doi.org/10.1016/j.applanim.2006.07.004.

Baciadonna, L., E. F. Briefer, L. Favaro, and A. G. McElligott. 2019. Goats distinguish between positive and negative emotion-linked vocalisations. Front. Zool. 16:25. https://doi.org/10.1186/s12983 -019-0323-z.

Bates, D., M. Mächler, B. M. Bolker, and S. C. Walker. 2015. Fitting linear mixed-effects models using lme4. J. Stat. Softw. 67. https:/ /doi.org/10.18637/jss.v067.i01.

Bishop, J. C., G. Falzon, M. Trotter, P. Kwan, and P. D. Meek. 2019. Livestock vocalisation classification in farm soundscapes. Comput. Electron. Agric. 162:531-542. https://doi.org/10.1016/j.compag 2019.04.020

Blumstein, D. T. 2007. The evolution, function, and meaning of marmot alarm communication. Adv. Stud. Behav. 37:371-401. https:/ /doi.org/10.1016/S0065-3454(07)37008-3.

Boersma, P., and V. van Heuven. 2001. Speak and unSpeak with Praat. Glot Int. 5:341-347.

Bolker, B. M., M. E. Brooks, C. J. Clark, S. W. Geange, J. R. Poulsen, M. H. H. Stevens, and J. S. S. White. 2009. Generalized linear mixed models: A practical guide for ecology and evolution. Trends Ecol. Evol. 24:127-135. https://doi.org/10.1016/j.tree.2008.10 .008 .

Briefer, E. F. 2012. Vocal expression of emotions in mammals: Mechanisms of production and evidence. J. Zool. (Lond.) 288:1-20. https: //doi.org/10.1111/j.1469-7998.2012.00920.x.

Briefer, E. F., A.-L. Maigrot, R. Mandel, S. B. Freymond, I. Bachmann, and E. Hillmann. 2015a. Segregation of information about emotional arousal and valence in horse whinnies. Sci. Rep. 5:9989. https://doi.org/10.1038/srep09989.

Briefer, E. F., F. Tettamanti, and A. G. McElligott. 2015b. Emotions in goats: Mapping physiological, behavioural and vocal profiles. Anim. Behav. 99:131-143. https://doi.org/10.1016/j.anbehav.2014 .11 .002 .

Briefer, E. F., E. Vizier, L. Gygax, and E. Hillmann. 2019. Expression of emotional valence in pig closed-mouth grunts: Involvement of both source- and filter-related parameters. J. Acoust. Soc. Am. 145:2895-2908. https://doi.org/10.1121/1.5100612.

Castellucci, G. A., M. J. McGinley, and D. A. McCormick. 2016. Knockout of Foxp2 disrupts vocal development in mice. Sci. Rep. 6:23305. https://doi.org/10.1038/srep23305.

Collier, K., S. W. Townsend, and M. B. Manser. 2017. Call concatenation in wild meerkats. Anim. Behav. 134:257-269. https://doi.org/ 10.1016/j.anbehav.2016.12.014.

Darwin, C. 1872. The Expression of the Emotions in Man and Animals. Dover Publications, London, UK.

Ede, T., B. Lecorps, M. A. G. Von Keyserlingk, and D. M. Weary. 2019. Symposium review: Scientific assessment of affective states in dairy cattle. J. Dairy Sci. 102:10677-10694. https://doi.org/10 $.3168 /$ jds.2019-16325.

Egge, A. R., Y. Brandt, and J. G. Swallow. 2011. Sequential analysis of aggressive interactions in the stalk-eyed fly Teleopsis dalmanni. Behav. Ecol. Sociobiol. 65:369-379. https://doi.org/10.1007/ s00265-010-1054-5.

Ellson, J., E.R. Gansner, E. Koutsofios, S.C. North, and G. Woodhull. 2003. Graphviz and Dynagraph-Static and dynamic graph drawing tools. Graph Drawing Software. Springer, New York, NY. https://doi.org/10.1007/978-3-642-18638-7_6.

Engesser, S., A. R. Ridley, and S. W. Townsend. 2017. Element repetition rates encode functionally distinct information in pied babbler 'clucks' and 'purrs'. Anim. Cogn. 20:953-960. https://doi.org/10 .1007/s10071-017-1114-6.
Favaro, L., E. F. Briefer, and A. G. McElligott. 2014. Artificial neural network approach for revealing individuality, group membership and age information in goat kid contact calls. Acta Acust. United Acust. 100:782-789. https://doi.org/10.3813/AAA.918758.

Filippi, P., M. Hoeschele, M. Spierings, and D. L. Bowling. 2019 Temporal modulation in speech, music, and animal vocal communication: evidence of conserved function. Ann. N. Y. Acad. Sci 1453:99-113. https://doi.org/10.1111/nyas.14228.

Flower, F. C., and D. M. Weary. 2001. Effects of early separation on the dairy cow and calf: 2. Separation at day 1 and 2 weeks after birth. Appl. Anim. Behav. Sci. 70:275-284. https://doi.org/10 .1016/S0168-1591(00)00164-7.

Friard, O., and M. Gamba. 2016. BORIS: A free, versatile open-source event-logging software for video/audio coding and live observations. Methods Ecol. Evol. 7:1325-1330. https://doi.org/10.1111/ 2041-210X.12584

Friard, O., and M. Gamba. 2019. Behatrix: Behavioral sequences analysis with permutations test. Accessed Nov. 4, 2019. http://www .boris.unito.it/pages/behatrix.

Golov, Y., A. Harari, J. Rillich, and A. Ayali. 2018. Precopulatory behavior and sexual conflict in the desert locust. PeerJ 6:e4356. https://doi.org/10.7717/peerj.4356.

Green, A., C. Clark, L. Favaro, S. Lomax, and D. Reby. 2019. Vocal individuality of Holstein-Friesian cattle is maintained across putatively positive and negative farming contexts. Sci. Rep. 9:18468. https://doi.org/10.1038/s41598-019-54968-4.

Green, A. C., I. N. Johnston, and C. E. F. Clark. 2018. Invited review: The evolution of cattle bioacoustics and application for advanced dairy systems. Animal 12:1250-1259. https://doi.org/10.1017/ S1751731117002646.

Hartig, F. 2019. DHARMa: Residual diagnostics for hierarchical (multi-level/mixed) regression models. $\mathrm{R}$ package version 0.3.2.0. https://CRAN.R-project.org/package=DHARMa.

Jensen, M. B. 2012. Behaviour around the time of calving in dairy cows. Appl. Anim. Behav. Sci. 139:195-202. https://doi.org/10 .1016/j.applanim.2012.04.002

Johnsen, J. F., K. Ellingsen, A. M. Grøndahl, K. E. Bøe, L. Lidfors, and C. M. Mejdell. 2015. The effect of physical contact between dairy cows and calves during separation on their post-separation behavioural response. Appl. Anim. Behav. Sci. 166:11-19. https:// doi.org/10.1016/j.applanim.2015.03.002.

Kershenbaum, A., D. T. Blumstein, M. A. Roch, C. Akçay, G. Backus, M. A. Bee, K. Bohn, Y. Cao, G. Carter, C. Cäsar, M. Coen, S. L. Deruiter, L. Doyle, S. Edelman, R. Ferrer-i-Cancho, T. M. Freeberg, E. C. Garland, M. Gustison, H. E. Harley, C. Huetz, M. Hughes, J. Hyland Bruno, A. Ilany, D. Z. Jin, M. Johnson, C. Ju, J. Karnowski, B. Lohr, M. B. Manser, B. Mccowan, E. Mercado III, P. M. Narins, A. Piel, M. Rice, R. Salmi, K. Sasahara, L. Sayigh, Y. Shiu, C. Taylor, E. E. Vallejo, S. Waller, and V. Zamora-Gutierrez. 2016. Acoustic sequences in non-human animals: A tutorial review and prospectus. Biol. Rev. Camb. Philos. Soc. 91:13-52. https://doi.org/10.1111/brv.12160.

Kiley, M. 1972. The vocalizations of ungulates, their causation and function. Z. Tierpsychol. 31:171-222. https://doi.org/10.1111/j .1439-0310.1972.tb01764.x.

Kovács, L., J. Tőzsér, F. L. Kézér, F. Ruff, M. Aubin-Wodala, E. Albert, A. Choukeir, Z. Szelényi, and O. Szenci. 2015. Heart rate and heart rate variability in multiparous dairy cows with unassisted calvings in the periparturient period. Physiol. Behav. 139:281-289. https://doi.org/10.1016/j.physbeh.2014.11.039.

Lenth, R. 2019. emmeans: Estimated marginal means, AKA leastsquares means. R package version 1.4.8. https://CRAN.R-project .org $/$ package $=$ emmeans

Lidfors, L. M. 1996. Behavioural effects of separating the dairy calf immediately or 4 days post-partum. Appl. Anim. Behav. Sci. 49:269283. https://doi.org/10.1016/0168-1591(96)01053-2.

Maigrot, A. L., E. Hillmann, and E. Briefer. 2018. Encoding of emotional valence in wild boar (Sus scrofa) calls. Animals (Basel) 8:85. https://doi.org/10.3390/ani8060085. 
Maigrot, A. L., E. Hillmann, C. Anne, and E. F. Briefer. 2017. Vocal expression of emotional valence in Przewalski's horses (Equus przewalskii). Sci. Rep. 7:8779. https://doi.org/10.1038/s41598-017 -09437-1.

Manser, M. B. 2001. The acoustic structure of suricates' alarm calls varies with predator type and the level of response urgency. Proc. Biol. Sci. 268:2315-2324. https://doi.org/10.1098/rspb.2001.1773.

Manteuffel, G., B. Puppe, and P. C. Schön. 2004. Vocalization of farm animals as a measure of welfare. Appl. Anim. Behav. Sci. 88:163182. https://doi.org/10.1016/j.applanim.2004.02.012.

McComb, K. E. 1991. Female choice for high roaring rates in red deer, Cervus elaphus. Anim. Behav. 41:79-88. https://doi.org/10.1016/ S0003-3472(05)80504-4.

McElligott, A. G., and T. J. Hayden. 1999. Context-related vocalization rates of fallow bucks, Dama dama. Anim. Behav. 58:10951104. https://doi.org/10.1006/anbe.1999.1237.

Meagher, R. K., A. Beaver, D. M. Weary, and M. A. G. von Keyserlingk. 2019. Invited review: A systematic review of the effects of prolonged cow-calf contact on behavior, welfare, and productivity. J. Dairy Sci. 102:5765-5783. https://doi.org/10.3168/jds.2018 $-16021$.

Meen, G. H., M. A. Schellekens, M. H. M. Slegers, N. L. G. Leenders E. van Erp-van der Kooij, and L. P. J. J. Noldus. 2015. Sound analysis in dairy cattle vocalisation as a potential welfare monitor. Comput. Electron. Agric. 118:111-115. https://doi.org/10.1016/j .compag.2015.08.028.

Mellor, D. J. 2015. Positive animal welfare states and encouraging environment-focused and animal-to-animal interactive behaviours. N. Z. Vet. J. 63:9-16. https://doi.org/10.1080/00480169.2014 .926800 .

Morton, E. S. 1977. On the occurrence and significance of motivation-structural rules in some bird and mammal sounds. Am. Nat. 111:855-869. https://doi.org/10.1086/283219.

Orbach, D. N., J. M. Packard, T. Kirchner, and B. Würsig. 2015. Evasive behaviours of female dusky dolphins (Lagenorhynchus obscurus) during exploitative scramble competition. Behaviour 152:1953-1977. https://doi.org/10.1163/1568539X-00003310.

Padilla de la Torre, M., E. F. Briefer, B. M. Ochocki, A. G. McElligott, and T. Reader. 2016. Mother-offspring recognition via contact calls in cattle, Bos taurus. Anim. Behav. 114:147-154. https:/ /doi.org/10.1016/j.anbehav.2016.02.004.

Padilla de la Torre, M., E. F. Briefer, T. Reader, and A. G. McElligott. 2015. Acoustic analysis of cattle (Bos taurus) mother-offspring contact calls from a source-filter theory perspective. Appl. Anim. Behav. Sci. 163:58-68. https://doi.org/10.1016/j.applanim.2014.11 .017 .

R Core Team. 2020. R: A Language and Environment for Statistical Computing. R Foundation for Statistical Computing, Vienna, Austria. https://www.R-project.org/.

Röttgen, V., F. Becker, A. Tuchscherer, C. Wrenzycki, S. Düpjan, P. C. Schön, and B. Puppe. 2018. Vocalization as an indicator of estrus climax in Holstein heifers during natural estrus and superovulation. J. Dairy Sci. 101:2383-2394. https://doi.org/10.3168/ jds.2017-13412.

RStudio Team. 2020. RStudio: Integrated Development Environment for R.

Sartori, C., M. B. Manser, and R. Mantovani. 2014. Relationship between number and intensity of fighting: Evidence from cow fighting tournaments in Valdostana cattle. Ital. J. Anim. Sci. 13:3286 https://doi.org/10.4081/ijas.2014.3286.
Scherer, K. R. 1986. Vocal affect expression-A review and a model for future research. Psychol. Bull. 99:143-165. https://doi.org/10 .1037/0033-2909.99.2.143.

Scheumann, M., A. E. Roser, W. Konerding, E. Bleich, H. J. Hedrich, and E. Zimmermann. 2012. Vocal correlates of sender-identity and arousal in the isolation calls of domestic kitten (Felis silvestris catus). Front. Zool. 9:36. https://doi.org/10.1186/1742-9994-9-36.

Schön, P. C., K. Hämel, B. Puppe, A. Tuchscherer, W. Kanitz, and G. Manteuffel. 2007. Altered vocalization rate during the estrous cycle in dairy cattle. J. Dairy Sci. 90:202-206. https://doi.org/10 .3168/jds.S0022-0302(07)72621-8.

Stěhulová, I., L. Lidfors, and M. Špinka. 2008. Response of dairy cows and calves to early separation: Effect of calf age and visual and auditory contact after separation. Appl. Anim. Behav. Sci. 110:144165. https://doi.org/10.1016/j.applanim.2007.03.028.

Tallet, C., P. Linhart, R. Policht, K. Hammerschmidt, P. Šimeček, P. Kratinova, and M. Špinka. 2013. Encoding of situations in the vocal repertoire of piglets (Sus scrofa): A comparison of discrete and graded classifications. PLoS One 8:e71841. https://doi.org/10 .1371/journal.pone.0071841.

Taylor, A. M., and D. Reby. 2010. The contribution of source-filter theory to mammal vocal communication research. J. Zool. (Lond.) 280:221-236. https://doi.org/10.1111/j.1469-7998.2009.00661.x.

Taylor, A. M., D. Reby, and K. Mccomb. 2009. Context-related variation in the vocal growling behaviour of the domestic dog (Canis familiaris). Ethology 115:905-915. https://doi.org/10.1111/j.1439 $-0310.2009 .01681 . x$.

von Keyserlingk, M. A. G., and D. M. Weary. 2007. Maternal behavior in cattle. Horm. Behav. 52:106-113. https://doi.org/10.1016/j yhbeh.2007.03.015.

Watts, J. M., and J. M. Stookey. 2000. Vocal behaviour in cattle: The animal's commentary on its biological processes and welfare. Appl. Anim. Behav. Sci. 67:15-33. https://doi.org/10.1016/S0168 -1591(99)00108-2.

Weary, D. M., and B. Chua. 2000. Effects of early separation on the dairy cow and calf 1 . Separation at $6 \mathrm{~h}, 1$ day and 4 days after birth. Appl. Anim. Behav. Sci. 69:177-188. https://doi.org/10 .1016/S0168-1591(00)00128-3.

Yeon, S. C., J. H. Jeon, K. A. Houpt, H. H. Chang, H. C. Lee, and H. J. Lee. 2006. Acoustic features of vocalizations of Korean native cows (Bos taurus coreanea) in two different conditions. Appl. Anim. Behav. Sci. 101:1-9. https://doi.org/10.1016/j.applanim .2006.01.013.

Yin, S., and B. McCowan. 2004. Barking in domestic dogs: Context specificity and individual identification. Anim. Behav. 68:343-355. https://doi.org/10.1016/j.anbehav.2003.07.016.

Zimmerman, P. H., P. Koene, and J. A. R. A. M. Van Hooff. 2000. The vocal expression of feeding motivation and frustration in the domestic laying hen, Gallus gallus domesticus. Appl. Anim. Behav. Sci. 69:265-273. https://doi.org/10.1016/S0168-1591(00)00136-2.

\section{ORCIDS}

Alexandra C. Green ( https://orcid.org/0000-0001-8357-5050

Lena M. Lidfors (ㄴ) https://orcid.org/0000-0002-5629-0946

Livio Favaro (ㄱ) https://orcid.org/0000-0002-8698-472X

Cameron E. F. Clark ( https://orcid.org/0000-0002-7644-2046 


\section{APPENDIX}

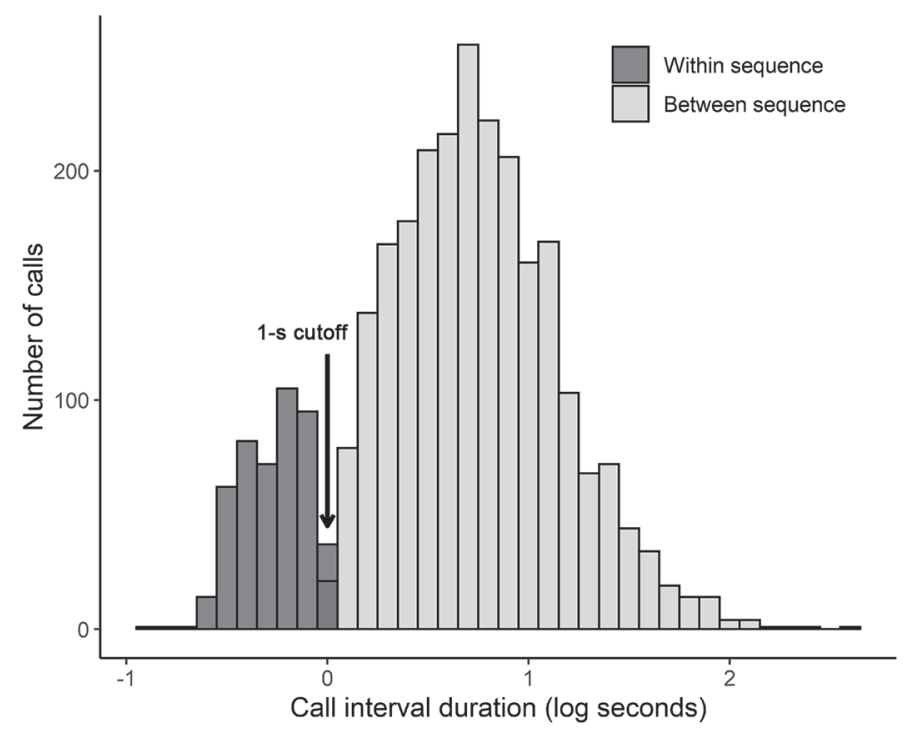

Figure A1. Histogram depicting the call interval duration distribution (log seconds) for within- and between-call sequences. The distribution was bimodal, with a 1-s $(\log 0)$ cutoff selected for the classification of within and between sequences, as this is the lowest point in the trough between the call interval durations.

Table A1. Likelihood ratio test model comparisons for the generalized linear mixed models (GLMM) and linear mixed models (LMM) for cow vocal parameters

\begin{tabular}{|c|c|c|c|c|c|c|}
\hline $\begin{array}{l}\text { Model } \\
\text { fitted }\end{array}$ & Variable & Model & df & $\mathrm{AIC}$ & $x^{2}$ & $P$-value \\
\hline \multirow{4}{*}{$\begin{array}{l}\text { Negative } \\
\text { binomial } \\
\text { GLMM }\end{array}$} & Closed-mouth calls & 1. (1|cow ID) & 3 & 536.85 & 5.96 & 0.015 \\
\hline & Mixed calls & 2. Context $+(1 \mid \operatorname{cow} \text { ID })^{*}$ & 4 & 381.69 & 7.46 & 0.006 \\
\hline & \multirow[t]{2}{*}{ Open-mouth calls } & 1. $(1 \mid$ cow ID $)$ & 3 & 330.68 & \multirow[t]{2}{*}{13.63} & \multirow[t]{2}{*}{0.0002} \\
\hline & & 2. Context $+(1 \mid \text { cow ID })^{*}$ & 4 & 319.05 & & \\
\hline \multirow{4}{*}{$\begin{array}{c}\text { Binomial } \\
\text { GLMM }\end{array}$} & \multirow{2}{*}{$\begin{array}{l}\text { Proportion of single isolated } \\
\text { calls }\end{array}$} & 1. $(1 \mid$ cow ID $)$ & 2 & $3,325.50$ & \multirow[t]{2}{*}{68.82} & \multirow[t]{2}{*}{$<0.0001$} \\
\hline & & 2. Context $+(1 \mid \text { cow ID })^{*}$ & 3 & $3,258.68$ & & \\
\hline & \multirow{2}{*}{$\begin{array}{l}\text { Proportion of repetitive call } \\
\text { sequences }\end{array}$} & 1. $(1 \mid$ cow ID $)$ & 2 & 284.30 & \multirow[t]{2}{*}{0.59} & \multirow[t]{2}{*}{0.44} \\
\hline & & 2. Context $+(1 \mid$ cow ID $)$ & 3 & 285.71 & & \\
\hline \multirow[t]{3}{*}{ LMM } & \multirow[t]{2}{*}{ Between-sequence interval } & 1. (1|cow ID) & 3 & $6,344.31$ & \multirow[t]{2}{*}{38.58} & \multirow[t]{2}{*}{$<0.0001$} \\
\hline & & 2. Context $+(1 \mid \text { cow ID })^{*}$ & 4 & $6,307.73$ & & \\
\hline & Within-sequence interval & 1. (1|cow ID/sequence ID) & 4 & 244.49 & 0.0018 & 0.97 \\
\hline
\end{tabular}

*Models selected for further statistical analyses, based on lower Akaike's information criterion (AIC) scores and significant $P$-values. 